\title{
Synthesis and Investigation of Nickel Nanoparticles
}

\author{
László Somlyai-Sipos ${ }^{1}$, Máté Czagány ${ }^{1}$, Dóra Janovszky ${ }^{2}$, Peter Baumli ${ }^{1 *}$ \\ ${ }^{1}$ Institute of Physical Metallurgy, Metalforming and Nanotechnology, University of Miskolc \\ Miskolc-Egyetemváros, Miskolc, H-3515, Hungary \\ femsomlyai@uni-miskolc.hu; femmatt@uni-miskolc.hu; *baumlipeter@gmail.com \\ ${ }^{2}$ ME-MTA, Materials Science Research Group, University of Miskolc \\ Miskolc-Egyetemváros, Miskolc, H-3515, Hungary \\ fekjd@uni-miskolc.hu
}

\begin{abstract}
The melting point is one of the most important thermodynamic properties of metallic materials. The melting point, that characterizes the bulk material is independent of the size in the microscopic range but will be size-dependent in the nano-range. The reason of this phenomenon is the high surface to volume ratio, thus the atoms situated on the surface play a greater role. One of the objectives of our research was to synthetize nickel nanoparticles (Ni NPs) using aqueous medium technology. The analysis of the produced particles was performed by X-ray diffraction (XRD) and Scanning electron microscopy (SEM). Furthermore, the main objective of our work was to determine the size dependence of the melting point of the produced nickel nanoparticles by differential scanning calorimetry (DSC).
\end{abstract}

Keywords: Nickel, Nanoparticle, Synthesis, Melting point depression, DSC.

\section{Introduction}

The nano-dimension opens a new way by changing the physical and/or chemical properties of the previously known macroscopic materials.

The use of nickel nanoparticles is widespread, e.g. in magnetic devices [1], as catalysts [2], in batteries [3] and electrochromatic devices [4], in fuel cells [5] and in sensors [6]. Numerous methods have been developed for the synthesis of nickel particles by researchers. Examples include polyol synthesis [7], electrochemical reduction [8], sol-gel technology [9], microwave heating [10], nucleation techniques [11] or organometallic precursor reduction [12].

In the case of nanoscale metals and alloys, different particle sizes have different melting points, thus allowing a drastic melting point depression compared to the macroscopic sizes. The reason for this phenomenon is the large surface to volume ratio, giving greater importance to the surface atoms. In the solid state, the cohesion energy of the atoms situated on the surface (due to the fewer adjacent atoms) is smaller than of the internal atoms. This phenomenon was first formulated by Pawlow [13] in 1909. Later, the effect of reducing the size of lead, tin, indium and bismuth was examined by Allen et al. [14] and it was found that the melting point decreases as the radius of the particles decreases. Many similar studies have been conducted afterwards for aluminium oxide [15], SAC ( $\mathrm{Sn3}, 5 \mathrm{Ag} 0,5 \mathrm{Cu})$ [16], gold [17], indium [18] and bismuth [19] confirming this phenomenon.

Recently, a model on the melting of nano-crystals in a one-component system was created by Végh et al. [20], where the solid phase was perfectly wetted by its own melt. As the basis for modelling, the case of lead (Pb) was taken, which was supported by experimental literature. According to their calculations, the critical particle size of lead was 4,7 $\mathrm{nm}$ and the calculated critical melting point was $220^{\circ} \mathrm{C}$. Below this critical size, the particle melted in its entire cross-section, while above this size, a solid core remained with a molten layer. Modelling of a $\mathrm{Cu} / \mathrm{AlN}$ nano-multilayer structure was reported by Kaptay et al [21]. According to their results, by reducing the thickness of the $\mathrm{Cu}$ layer to $10 \mathrm{~nm}$, a depression of the melting point up to $609^{\circ} \mathrm{C}$ can be achieved. The development and investigation of this $\mathrm{Cu} / \mathrm{AlN}$ multilayers were carried out by Lehmert et al. [22] confirming the possibility of creating a $\mathrm{Cu}$ brazing joint at a temperature of $750^{\circ} \mathrm{C}$, much below of the bulk melting point of $1083^{\circ} \mathrm{C}$.

In the present paper, our goal was to prepare nickel nanoparticles from aqueous solution by reduction method. To the best of our knowledge, the melting point of the nickel nanoparticles is determined here for the first time. 


\section{Experimental procedure}

The bath ingredients used in our experiments were nickel chloride $\left(\mathrm{NiCl}_{2}\right)$, ethylene glycol $\left(\mathrm{C}_{2} \mathrm{H}_{4}(\mathrm{OH})_{2}\right)$, sodium hydroxide $(\mathrm{NaOH})$ and hydrazine monohydrate $\left(\mathrm{N}_{2} \mathrm{H}_{4} \cdot \mathrm{H}_{2} \mathrm{O}\right)$. As a first step, $0.1416 \mathrm{~g}$ of $\mathrm{NiCl}_{2}$ salt was dissolved in 30 $\mathrm{ml}$ of ethylene glycol. After dissolution, $1.2 \mathrm{~g} \mathrm{NaOH}$, then finally $183 \mu \mathrm{L} \mathrm{N}_{2} \mathrm{H}_{4} \cdot \mathrm{H}_{2} \mathrm{O}$ was added. In order to use the evolving $\mathrm{N}_{2}$ gas as a protective atmosphere, the system was closed on top. The solution was kept in a $60^{\circ} \mathrm{C}$ water bath for 1 hour with continuous stirring. After that, the bath was poured into an Eppendorf tube and the solid particles were separated from the solution using a centrifuge (Centrifuge 5804R). The centrifugation was performed at $4000 \mathrm{rpm}$ at $20^{\circ} \mathrm{C}$. After the separation from the bath, in order to dispart the agglomerated particles, the process was repeated three times with distilled water for a duration of 5-5 minutes and finally for 12 minutes with ethyl alcohol. The purified particles were then dispersed in ethyl alcohol and then subjected to an investigation of scanning electron microscopy (Hitachi S4800).

The determination of the melting point of $\mathrm{Ni}$ nanoparticles was carried out by differential scanning calorimetry (Netzsch STA 449 F3 Jupiter TG-DSC). The weight of the measured Ni nanoparticles was $31 \mathrm{mg}$, a heating rate of $35^{\circ} \mathrm{C} / \mathrm{min}$ was applied to reach $1300^{\circ} \mathrm{C}$, than after a $2 \mathrm{~min}$ isotherm period $7^{\circ} \mathrm{C} / \mathrm{min}$ to $1500^{\circ} \mathrm{C}$. As a protective environment, pure argon gas (99.9999\% by volume) was used. A piece of titanium getter was placed in the vicinity of the sample, serving as an oxygen trap.

\section{Result and discussion}

\subsection{Synthesis of nickel nanoparticles}

The precipitated $\mathrm{NiCl}_{2}$ and $\mathrm{NaOH}$ in the ethylene glycol resulted in a light brownish solution, and after adding $\mathrm{N}_{2} \mathrm{H}_{4} \cdot \mathrm{H}_{2} \mathrm{O}$, the solution became black indicating the formation of nickel particles. The SEM image (Fig. 1) shows that the particles have a size of about 100-150 nm, however forming agglomerates.
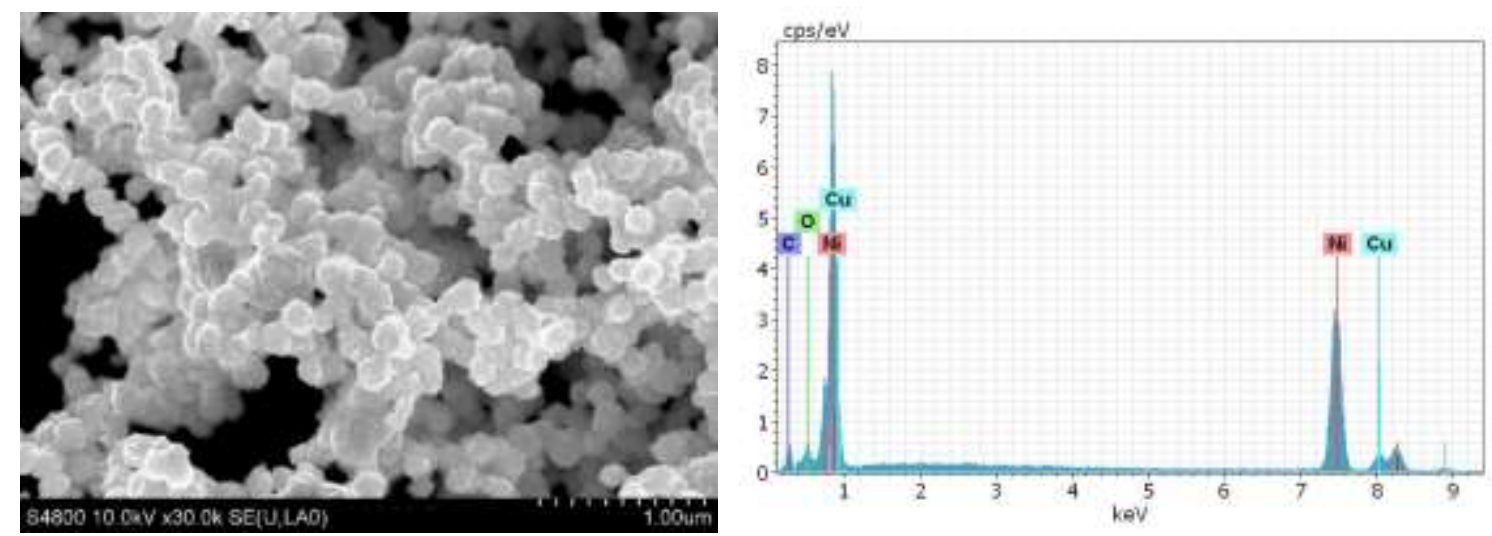

Fig. 1: The SEM photography and the EDS analysis of the nickel particles.

The EDS spectrum indicates the presence of oxygen beside nickel, suggesting that some of the particles could have been partially oxidized, presumably during the process of centrifugation and drying of Ni NPs. The presence of $\mathrm{Cu}$ and $\mathrm{C}$ is attributed to the grid containing the particles. The X-ray diffraction measurement confirms the results of scanning electron microscopy that pure nickel particles were synthesized (Fig. 2). The broader reflexions of Ni indicate that some of the nickel particles are amorphous to the XRD investigation. 


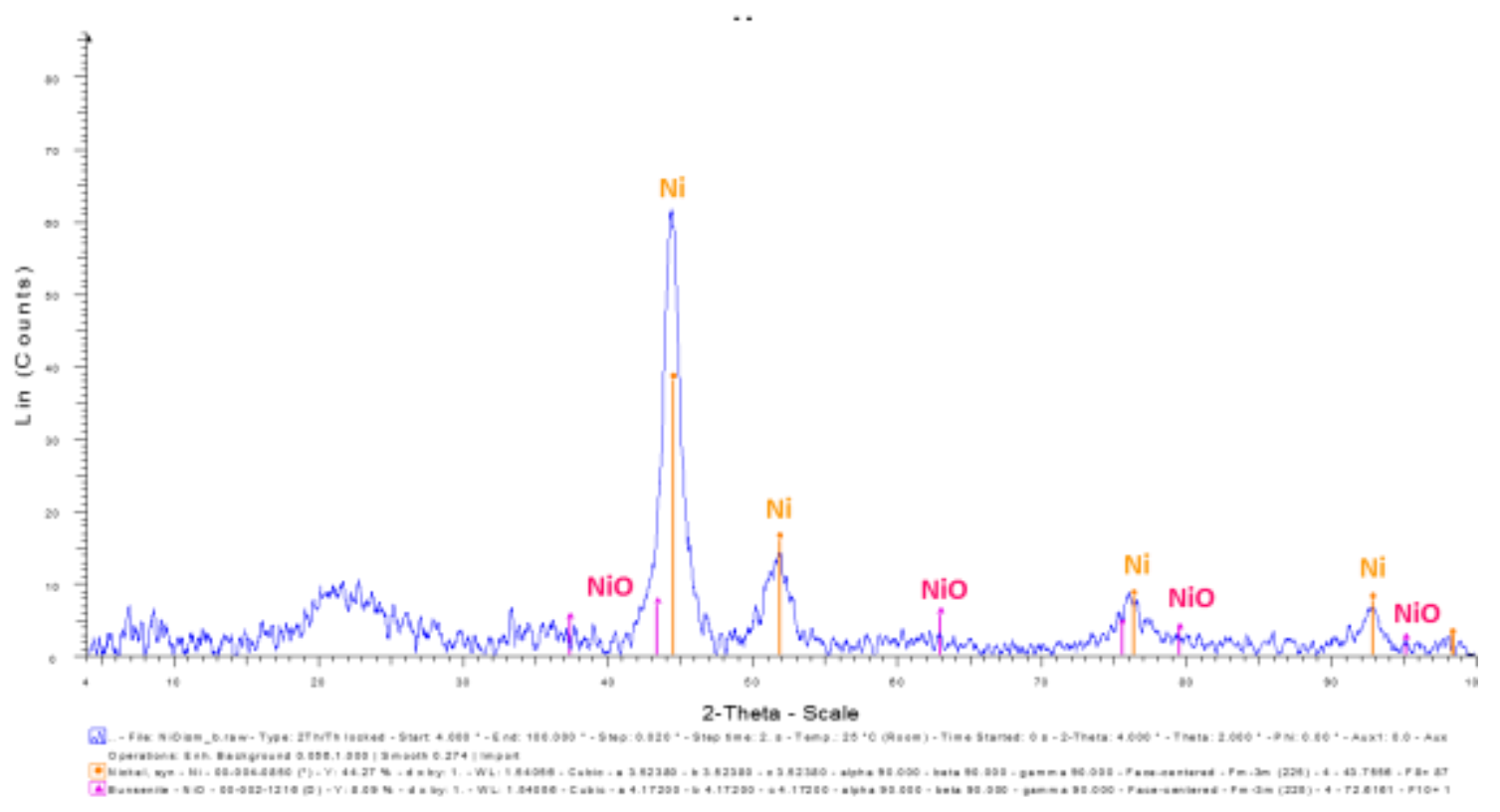

Fig. 2: XRD pattern of the nickel particles.

\subsection{Melting point depression of the nickel particles}

The melting point of the nickel-oxygen eutectic is $1440^{\circ} \mathrm{C}$, so the melting of our sample began with the melting of nickel $\left(1438.5^{\circ} \mathrm{C}\right)$ in the inside of the oxidized Ni particles (Fig. 3.). This proves that the titanium getter had a positive effect on the oxidation of the particles even though it could not completely prevent it. The total melting point depression thus was $17^{\circ} \mathrm{C}$ compared to the melting point of the pure, bulk nickel $\left(1455^{\circ} \mathrm{C}\right)$.

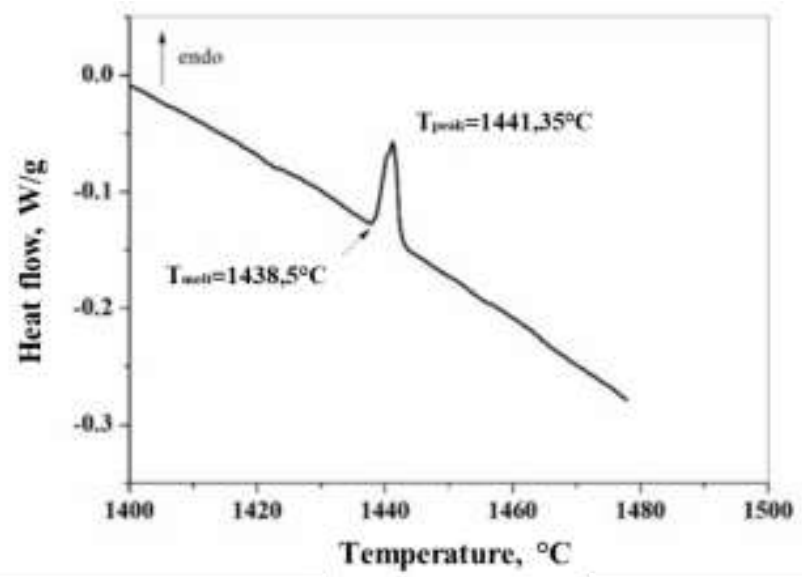

Fig. 3: DSC scans of the Ni particles.

The DSC study refers to the transformation of the original 100-150 nm nickel particles into a core-shell structure as a consequence of the oxidization of the pure nickel particles over time. Due to the oxidation, the size of the pure nickel particle was decreased. In fact, in this spontaneous core-shell structure, the size of the nickel particles was reduced below $10 \mathrm{~nm}$ and as mentioned in the literature, the decrease in the melting point was observed.

\section{Conclusion}

In summary, nickel particles were successfully synthesized during our experiments. Due to the small size and the resulting high specific surface area of these particles, they could be easily oxidized during the sample cleaning and further 
preparation processes. Scanning electron microscopic examinations were performed to determine the size and morphology of the particles from which it could be concluded that the resulting particles were rapidly agglomerated. On the basis of X-ray diffraction analysis and transmission electron microscopy, it can be stated that pure nickel particles were synthetized. With the help of the differential scanning calorimetry a melting point depression of $17^{\circ} \mathrm{C}$ was measured for nickel as a result of the reduction of the particle size. In our future work, our aim is to increase the amount of the produced nickel particles, and further reducing their size, thus supporting the melting point depression caused by size reduction.

\section{Acknowledgements}

The described article was carried out as part of the GINOP-2.3.2-15-2016-00027 "Sustainable operation of the workshop of excellence for the research and development of crystalline and amorphous nanostructured materials" project implemented in the framework of the Szechenyi 2020 program. The realization of this project is supported by the European Union. Special thanks for the Innovációs Laboratórium Kft for SEM and Dr. István Kocserha for X-ray investigations.

\section{References}

[1] S. Ingole, P. Manandhar, J.A. Wright, E. Nazaretski, J.D. Thompson, S.T. Picraux, "Assembly and magnetic properties of nickel nanoparticles on silicon nanowires," Appl. Phy. Let., vol. 94, pp. 223118-1-3, 2009.

[2] J. Aguilhon, C. Boissière, O. Durupthy, C. Thomazeau, C. Sanchez, "Nickel nanoparticles with controlled morphologies application in selective hydrogenation catalysis," Studies in Sur. Sci. and Cat., pp. 521-524, 2010.

[3] E. Hosono, S. Fujihara, I. Honma, H. Zhou, "The high power and high energy densities Li ion storage device by nanocrystalline and mesoporous Ni/NiO covered structure,” Electrochem. Com., vol. 8, pp. 284-288, 2006.

[4] E. O. Zayim, I. Turhan, F.Z. Tepehan, N. Ozer, "Sol-gel deposited nickel oxide films for electrochromic applications," Solar E. Mater. and Solar Cells, vol. 92, pp. 164-169, 2008.

[5] R. M. A. Tehrani, S. A. Ghani, "The nanocrystalline nickel with catalytic properties on methanol oxidation in alkaline medium," Fuel Cells, vol. 9, pp. 579-587, 2009.

[6] N. Sattarahmady, H. Heli, R. D. Vais, "An electrochemical acetylcholine sensor based on lichen-like nickel oxide nanostructure," Biosen. and Bioelect., vol. 48, pp. 197-202, 2013.

[7] E.G.C. Neiva, M. F. Bergamini, M. M. Oliveira, L. H. Marcolino Jr., A. J. G. Zarbin, "PVP-capped nickel nanoparticles: Synthesis, characterization and utilization as a glycerol electro sensor," Sens. and Act. B, vol. 196, pp. 574-581, 2014.

[8] Y. T. Jeon, J. Y. Moon, G. H. Lee, J. Park, Y. Chang, "Comparison of the Magnetic Properties of Metastable Hexagonal Close-Packed Ni Nanoparticles with Those of the Stable Face-Centered Cubic Ni Nanoparticles," J. Phys. Chem. B, vol. 110, pp. 1187-1191, 2006.

[9] J. Yang, B. Feng, Y. Liu, Y. Zhang, L. Yang, Y. Wanga, M. Wei, J. Lang, D. Wang, X. Liu, "Phase transition and magnetic properties of Mg-doped hexagonal close-packed Ni nanoparticles," Appl. Surf. Sci. vol. 254, pp. 7155-7158. 2008.

[10] C. Parada, E. Morán, "Microwave-assisted synthesis and magnetic study of nanosized Ni/NiO materials," E. Chem. Mater, vol. 18, pp. 2719-2725, 2006.

[11] M. Grzelczak, J. Perez-Juste, B. Rodriguez-Gonzalez, M. Spasova, I. Barsukov, M. Farle, L. M. Liz-Marzan, "Ptcatalyzed growth of Ni nanoparticles in aqueous CTAB solution," Chem. Mater, vol. 20, pp. 5399-5405, 2008.

[12] Y. Chen, X. Luo, G. H. Yue, X. Luo, D. L. Peng, "Synthesis of iron-nickel nanoparticles via a nonaqueous organometallic route," Mater. Chem. Phys. vol. 113, 412-416, 2009.

[13] P. Pawlow, "Über die Abhängigkeit des Schmelzpunktes von der Oberflächenenergie eines festen Körpers," Z. Phys. Chem. vol. 65, pp. 545-548, 1909.

[14] G. L. Allen, R. A. Bayles, W. W. Gile, W. A. Jesser, "Small particle melting of pure metals," Thin Solid Films, vol.144, pp. 297-308, 1986.

[15] N. Joshi, N. Mathur, T. Mane, D. Sundaram, "Size effect on melting temperatures of alumina nanocrystals: Molecular dynamics simulations and thermodynamic modelling," Comp. Mater. Sci, vol. 145, pp. 140-153, 2018. 
[16] H. J. Kim, S. P. Jang, J. H. Lee, Y. J. Park, "Transformation of SAC (Sn3.0Ag0.5Cu) nanoparticles into bulk material during melting process with large melting-point depression," Micro \& Nano Letters, vol. 11, pp. 840-843, 2016.

[17] P. Buffat, J. P. Borel, "Size effect on the melting temperature of gold particles," Phys. Rev. A, vol. 13, pp. 2287-2298, 1976.

[18] M. Zhang, M. Yu. Efremov, F. Schiettekatte, E. A. Olson, A. T. Kwan, S. L. Lai, T. Wisleder, J. E. Greene, L. H. Allen, "Size-dependent melting point depression of nanostructures: Nanocalorimetric measurements," Phys. Rev. B, vol. 62, pp. 10549-10557, 2000.

[19] G. Kellermann, A. F. Craievich, "Structure and melting of Bi nanocrystals embedded in a B2O3-Na2O glass," Phys. Rev. B, vol. 65, pp. 134204-1-6, 2002.

[20] A. Vegh, G. Kaptay, "Modelling surface melting of macro-crystals and melting of nano-crystals for the case of perfectly wetting liquids in one-component systems using lead as an example," Calphad, vol. 63, pp. 37-50, 2018.

[21] G. Kaptay, J. Janczak-Rusch, L. P. H. Jeurgens, "Melting Point Depression and Fast Diffusion in Nanostructured Brazing Fillers Confined Between Barrier Nanolayers," J. of Mater. Eng. and Perf., vol. 25, pp. 3275-3284, 2016.

[22] B. Lehmert, J. Janczak-Rusch, G. Pigozzi, P. Zuraw, F.L. Mattina, L. Wojarski, W. Tillmann, L.P.H. Jeurgens. "Copper-Based Nanostructured Coatings for Low-Temperature Brazing Applications," Materials Transactions, vol. 56, pp. 1015-1018, 2015. 